\title{
Pescaria subversiva: um ato de comunicar a r-e-xistência dos povos e comunidades tradicionais do Rio Xingu
}

\author{
Subversive Fishing: An Act of Communicating the Re-Existence of \\ Traditional Communities of the Xingu River
}

\author{
Pesca subversiva: un acto de comunicación de la existencia real de \\ los pueblos y comunidades tradicionales del río Xingu
}

Ana Laide Soares Barbosa (Universidade de Brasília, Brasil)*

https://doi.org/10.22409/poiesis.v22i37.47257

RESUMO: Por meio da arte de pescar, dos nossos saberes culturais e dos conhecimentos tradicionais, realizamos a Pescaria Subversiva, com o objetivo de defender o rio Xingu contra o complexo hidroelétrico de Belo Monte e visibilizar os(as) pescadores(as) que viviam desse rio. Materializamos a subjetividade simbólica que o rio exercia naqueles que o viam como pai e mãe; o antropocentrismo de mercantilização da natureza; a solidariedade entre os que pescavam; a identificação dos locais tradicionais de pesca; suas delimitações, conflitos socioambientais; e a falta de políticas públicas para os pescadores artesanais. Atualmente o rio está morrendo aos poucos e, com ele, centenas de vidas. Há ameaça de transformar o que restou do seu leito, na vazão reduzida, em polo de mineração.

PALAVRAS-CHAVE: Rio Xingu; território tradicional de pesca; pescadores(as); resistência

\footnotetext{
* Ana Laide Soares Barbosa é educadora social, componente do Movimento Xingu Vivo para Sempre na cidade de Altamira, Pará, graduada em Etnodesenvolvimento pela Universidade Federal do Pará (UFPA) e mestranda no Programa de Pós-Graduação em Sustentabilidade junto a Povos e Territórios Tradicionais, na Universidade de Brasília (UnB). E-mail: analaidesoares@gmail.com. Orcid: 00000002-5998-0096.
} 
ABSTRACT: Through the art of fishing and our cultural and traditional knowledge, we carried out the Subversive Fishing in order to defend the Xingu River against the Belo Monte hydroelectric complex and to make the fishermen who lived on this river visible. We materialized the symbolic subjectivity that the river exercised in those who saw it as father and mother; the anthropocentrism of the commodification of nature; the solidarity among those who fished; the identification of traditional fishing sites, their boundaries, socio-environmental conflicts and the lack of public policies for artisanal fishermen. Currently the river is dying little by little and with it, hundreds of lives. The threat to transform what remained of its bed in the reduced flow into a mining complex.

KEYWORDS: Xingu River; traditional fishing territory; fishermen; resistance

RESUMEN: A través del arte de la pesca, nuestro conocimiento cultural y el conocimiento tradicional, llevamos a cabo la Pesca Subversiva para defender el río Xingu contra el complejo hidroeléctrico Belo Monte y hacer visibles a los pescadores que vivían en este río. Materializamos la subjetividad simbólica que ejercía el río en quienes los veían como padre y madre; el antropocentrismo de la mercantilización de la naturaleza; la solidaridad entre los que pescaban; la identificación de sitios de pesca tradicionales, sus límites, conflictos socioambientales y la falta de políticas públicas para los pescadores artesanales. Actualmente el río está muriendo poco a poco y con él cientos de vidas. La amenaza de transformación de lo que quedaba de su lecho en el flujo reducido en un polo minero.

PALABRAS CLAVE: Río Xingu; territorio pesquero tradicional; pescadores; resistencia.

Citação recomendada:

BARBOSA, Ana Laide Soares. Pescaria subversiva: um ato de comunicar a r-e-xistência dos povos e comunidades tradicionais do Rio Xingu. Revista Poiésis, Niterói, v. 22, n. 37, p. 151-164, jan./jun. 2021. [https://doi.org/10.22409/poiesis.v22i37.47257]

\section{(cc) BY-NC-ND}

Este documento é distribuído nos termos da licença Creative Commons Atribuição-NãoComercial 4.0 Internacional (CC-BY-NC) (c) 2021 Ana Laide Soares Barbosa

Ana Laide Soares Barbosa, Pescaria subversiva: um ato de comunicar a r-e-xistência dos povos e... 


\section{Pescaria subversiva: um ato de comunicar a r-e-xistência dos povos e comunidades tradicionais do Rio Xingu}

A época do banquete do rio

"Sou um pescador sem rio

Pescador que sonha

Pescador que luta

Pescador que pensa um dia

Realizar um sonho

Um sonho de voltar a pescar

Um sonho de voltar a viver

Um sonho de voltar a sorrir

Porque tudo isso eu perdi

Perdi pra dar lugar a um monstro

Se chama Belo Monte [...]"

--- Élio Alves da Silva
Era 11 de março de 2011. Cerca de 250 pescadores e pescadoras das margens do médio e baixo Rio Xingu, parte do estado do Pará, dos municípios de Porto de Moz, Senador José Porfírio, Vitória do Xingu e Altamira, organizaram um ato de desobediência civil. Ao posicionarem-se contra a construção da barragem da Hidroelétrica de Belo Monte, infringiram a Lei 7.653, de 12 de fevereiro de 1988, que proíbe a pesca no período da piracema. 
A ação, organizada pelas pescadoras e pescadores, chamou-se A Grande Pescaria: em Defesa do Rio Xingu Contra Belo Monte. Pescaram por três dias e três noites no período do defeso. O levante desafiava o Estado, que acabara de conceder à Norte Energia licença de instalação para a construção da Hidrelétrica.

Os pescadores e pescadoras dos referidos municípios perceberam as movimentações frenéticas entorno da obra de Belo Monte: homens chegando de todos os cantos do Brasil, enchendo os baixões ${ }^{1}$, as quitinetes $^{2}$, hotéis. Até os quartos desocupados das residências de moradores antigos serviram de pousadas. Houve o aumento do comércio de materiais de construção, as máquinas pesadas chegando pelo Rio Xingu e pela rodovia transamazônica, a multiplicação da frota de voadeiras e o crescimento do fluxo de embarcações no rio.

Por conta dessa realidade abrupta na região, iniciamos nossa peregrinação, de reunião em reunião, nos órgãos públicos: Instituto Brasileiro de Meio Ambiente (IBAMA), Casa de governo, Defensoria Pública do Estado (DPE), Secretaria do Patrimônio da União (SPU), Ministério Públi- co Federal (MPF) e outros órgãos do estado e municípios. Nesses espaços, buscava-se a defesa dos direitos que já estavam sendo violados.

As colônias de pescadores(as), os movimentos sociais e as organizações não governamentais (ONGs) contribuíam na produção e difusão de informações: a respeito dos impactos que já enfrentávamos, tanto na invasão do território tradicional de pesca como no processo de expulsão das ilhas, e na organização dos grupos de pescadores(as), barqueiros, areeiros, carroceiros, oleiros, ribeirinhos e indígenas. Mas eram tantas reuniões e tão poucas ações. Seu Pedrinho (pescador da Ilha da Fazenda) contou que chegou a participar mais de 10 reuniões em apenas um mês.

Pressentindo que a perda do rio estava se aproximando, a dor e a solidão eram visíveis em suas faces e em suas palavras. Essa realidade os fez reagir. Assim, em fevereiro de 2011, um grupo de seis muIheres pescadoras e indígenas (Josefa, Juma Xipaia, Sheila Juruna, Edisangela, Fabiana Xipaia e eu) tiveram uma ideia para dar visibilidade às pescadoras e pes-

Ana Laide Soares Barbosa, Pescaria subversiva: um ato de comunicar a r-e-xistência dos povos e... 
cadores, como protetoras e protetores do rio, e ao rio como fonte de vidas.

A partir dessa reunião, iniciamos nos baixões de Altamira, nas ilhas e municípios (baixão do Tufi, Igarapé, Altamira, Açaizal, Independente II, Boa Esperança, Rua do Ferreiro, Rua da Olaria, Peixaria, Furo da Trindade, Vila Belo Monte, Ilha da Fazenda e Vila Ressaca), reuniões com os(as) pescadores(as) sobre a ausência deles(as) em todos os processos de implantação de Belo Monte. As mobilizações se estenderam para outros municípios (Brasil Novo, Medicilândia, Porto de Moz, Vitória e Senador José Porfírio).

\section{Tecendo a Rede}

Eu, como pescadora, era parte desse processo que estava sendo construído. Uma rede de pesca foi o símbolo de resistência, escolhido para nos comunicar e resistir com os grupos de pescadores e pescadoras que se articulavam em defesa do rio Xingu. Em cada reunião que realizávamos, tecíamos um pedaço da rede, dávamos um nó em nossa resistência, em favor dos(as) pescadores(as) e do rio, contra Belo Monte.

A rede da resistência caminhava conosco, de reunião em reunião, em cada local que se preparava para o grande banquete que o Xingu iria ofertar para seus filhos e fiIhas. Nos baixões de Altamira, era nosso instrumento mais relevante, servindo-nos de símbolo, pauta, narrativas místicas, vivências, histórias ancestrais, proteção do meio ambiente, economia partilhada, cultura, organização social e defesa do território ancestral. Ensinada pelo Xingu aos seus parentes.

A rede de pesca era o elo entre o passado e o presente, entre o velho e o novo, entre o atraso e o desenvolvimento. Para nós, amazônidas xinguaras, não nos deixaram escolhas. Nossos sonhos e desejos aos poucos iam se diluindo, feito as fumaças das ilhas e matas queimadas para o desenvolvimento, à medida que a obra ia avançando. Os grupos que se encontravam nas reuniões viam um fio de esperança sendo tecido, um nó apertado no laço da aliança que precisavam para a realização da Pescaria. 
Assim, as memórias iam tomando formas e reivindicavam seus direitos: ao rio livre, à soberania alimentar, à sua autonomia, à liberdade de exercer sua atividade, seu lazer, seus modos de vidas e sua relação com o território pesqueiro. Esses elementos não faziam parte do Estudo de Impactos Ambientais (EIA) de Belo Monte, e menos ainda a sabedoria ancestral como patrimônio material e imaterial dos povos das águas do Rio Xingu.

A Pescaria desvela, revela os verdadeiros donos do Rio Xingu. Os nós da rede fortaleciam-se em cada curva do rio, as vozes dos(as) pescadores(as) estrondavam em suas margens e paranás, despertando os encantados das profundezas daquelas águas límpidas de corredeiras. Convocados aos apelos dos povos tradicionais, imediatamente agem. Reunidos nas cidades encantadas, decidem participar da Grande Pescaria, enchendo as redes, telas e linhas de todas as espécies de peixes (13 toneladas foram pescadas), além de garantir a proteção dos pescadores e suas famílias durante a pesca subversiva em defesa de suas moradas territoriais.
Os impactos de Belo Monte sobre a pesca também eram medidos por especialistas das academias. Segundo o relatório de impacto ambiental (RIMA) de Belo Monte, realizado pelo IBAMA, concluiu-se que "os peixes que vivem nesses igarapés e que dependem das planícies que serão inundadas, sofrerão consequências negativas, com o desaparecimento de espécies" (MINISTÉRIO DE MINAS E ENERGIA DO BRASIL, 2009, p. 101).

\author{
Análise feita por pesquisadores e cientistas de \\ diversas áreas, componentes do painel de es- \\ pecialistas, criado para produzir estudos inde- \\ pendentes sobre os impactos de Belo Monte, \\ conclui que: tanto os peixes que se movimen- \\ tam na direção de jusante para montante da \\ barragem (em busca de sítios para as deso- \\ vas), como também os que se movimentam no \\ sentindo inverso, de montante para jusante \\ (em busca de sítios para alimentação) serão \\ afetados. 0 impacto decorre tanto da ação da \\ barragem (impedimento de subida), como do \\ canal lateral e do reservatório (condições to- \\ talmente distintas em relação ao canal natural \\ do rio). 0 empreendimento AHE Belo Monte, \\ do ponto de vista da ictiofauna, é tecnicamen- \\ te inviável, visto que irá destruir uma grande \\ extensão de ambientes de corredeiras tanto no
}

Ana Laide Soares Barbosa, Pescaria subversiva: um ato de comunicar a r-e-xistência dos povos e... 
trecho de vasão reduzida quanto na área do

lago. Não existe compensação ambiental a altura desses impactos sobre a ictiofauna. (XINGUVIV0, 2011).

O encontro de saberes entre os povos tradicionais e os pesquisadores diagnosticou um cenário catastrófico sobre o rio. Todos tinham pressa em fazer uma comunicação contra-hegemônica sobre o empreendimento. E a forma que os povos tradicionais encontraram foi a pesca subversiva, envolvendo o povo que seria afetado através das rodas de conversas, reuniões, divulgação de rua, utilizando as moto-som, rádios e a Pescaria Subversiva. Esses foram os canais encontrados para se comunicarem com este mundo e o mundo dos encantados, com a sociedade local, regional e nacional.

Este caminho de comunicar o que os(as) pescadores(as) estavam vivendo foi o instrumento utilizado para fazer essa comunicação relacional. Comunicando à sociedade a partir da sua própria linguagem e práticas (VANNUCHI, 2018).

\section{Considerações finais}

A Pescaria subversiva trouxe alguns elementos que muito contribuem para tornar público o significado do rio para a continuidade das vidas que dele dependem, tais como o conhecimento tradicional, a cultura, a culinária, a cosmovisão, a organização social, os conflitos socioambientais, a autogovernança e a autonomia dos(as) pescadores(as) do Xingu. A seguir, pontuo alguns desses elementos, significativos para a vida dos que marcam suas existências a partir do território das águas:

Conflito socioambiental: A Pescaria Subversiva foi um ato político contra os projetos desenvolvimentistas do governo para a Amazônia. Ainda que os(as) pescadores(as) tenham dificuldades na compreensão do termo, entenderam que o governo estava tirando sem permissão, do rio e das suas populações, o elemento mais valioso para as suas existências: a água, contradizendo a sua própria política ambiental, positivada na lei no $7.653 / 88$, que garante a piracema. 
Suicida da própria lei, o governo fez isso quando decidiu, de forma autoritária, barrar o rio Xingu, colocando em risco de extinção sua fauna e flora, principalmente espécies endêmicas, a exemplo do acari zebra (Hypancistrus zebra), que só existe na região chamada Volta Grande, no rio Xingu. A atitude do governo foi tão vergonhosa e antiética que seus órgãos de fiscalização, como o IBAMA, não tiveram coragem de fiscalizar naqueles dias de defeso.

\section{Autogovernança e autonomia: Os(As)} pescadores(as), ao decidirem sair para ram que tinham o direito de fazê-la. Para chegarem a essa decisão, levaram do mês de fevereiro de 2011 até o dia 11 de março, reunindo, planejando, analisando os riscos, decidindo tudo coletivamente. Para isso acontecer, era preciso fazer parcerias com outros movimentos sociais e ONGs. Pois sabíamos que Altamira era o canteiro de obras da Belo Monte e também das Forças Armadas do Estado, preparadas para coibir qualquer ação popular contra à obra.

A decisão que foi tomada mostrou ao governo, armado até os dentes, a gover-

nança dos(as) pescadores(as) artesanais sobre o seu território. Pôs à prova a autonomia de quem conhece o rio, ao fazer 3 dias e 3 noites de pesca, incorporando nesse ato suas sabedorias, criatividades, seus corpos e sentidos. Toda sua produção foi doada para centenas de pessoas da cidade de Altamira, num gesto autônomo e solidário, para que entendessem o quanto o rio Xingu era generoso com seus filhos. E que é preciso salvá-lo.

Ao comparar com a governança autoritária do Estado brasileiro, que decidiu de forma autoritária a nova função das águas do rio Xingu, olhando-a como um mero recurso natural a ser explorado, num modelo ultrapassado de extrativismo, de acumulação capitalista, voltado para grupos e empresas transnacionais da mineração (Belo Sun), do agronegócio, dos madeireiros, percebe-se que o governo enfraquece cada vez mais suas estruturas de governança hegemônica.

Por outro lado, os povos das águas do Xingu precisaram de menos de dois meses para ensinar a todas(os) como exercerem a autogovernança e a autonomia de forma coletiva. Sem ferir o curso natural das

Ana Laide Soares Barbosa, Pescaria subversiva: um ato de comunicar a r-e-xistência dos povos e... 
águas do Xingu, sem extinguir as milhares de vidas que dele dependiam e ainda dependem. Garantindo a segurança e a soberania alimentar para os que mais precisam. É claro que essas reflexões não se esgotam neste pequeno texto, mas são pertinentes nestes tempos.

Comunicação que nasce das águas: A forma mais eficaz para que se falasse dos(as) pescadores(as), possibilitando que saíssem do anonimato no período de Belo Monte, foi através da comunicação dos seus próprios corpos pescando, demostrando a todas o seu conhecimento tradicional, invisível a muitos olhares. A comunicação do próprio rio cedeu o que tinha de mais precioso para a humanidade: os seus peixes. Alimentou por muitas gerações os seres humanos que aqui passaram e, apesar de estar agonizando, ainda alimenta os que sobreviveram a Belo Monstro.

Cito algumas fontes que veicularam a Pescaria Subversiva nos jornais. Redes sociais como: Comissão Pastoral da Terra (CPT) nacional (2011), Amanbai notícias (2011), Blog Manuel Dutra (2011), Jornal de Brasília (2011) e Xingu Vivo (2011).
Para chegar a esses veículos convencionais de comunicação, os(as) pescadores(as) tiveram que fazer a sua própria comunicação interna. Esse caminho de comunicar o que os(as) pescadores(as) estavam vivendo foi o instrumento utilizado para fazer a comunicação relacional; comunicando à sociedade a partir da sua própria linguagem e práticas (VANNUCHI, 2018).

A Pescaria foi a primeira ação nesse período da construção de Belo Monte, realizada na luta de resistência dos povos dessas águas, em defesa do rio Xingu, contra Belo Monte. Após esse ato, em 2013, aconteceu o acampamento dos pescadores, que durou 33 dias, nas ilhas que hoje estão submersas pelo reservatório da usina. Esses dois atos, e as inúmeras reuniões mencionadas acima, originaram a criação do Conselho dos Ribeirinhos do Reservatório de Belo Monte, no processo de retomada do território, retornando para as margens do reservatório cerca de 300 famílias que foram expulsas do rio pela Norte Energia, descaracterizando seus modos de vida e relação com o território. 


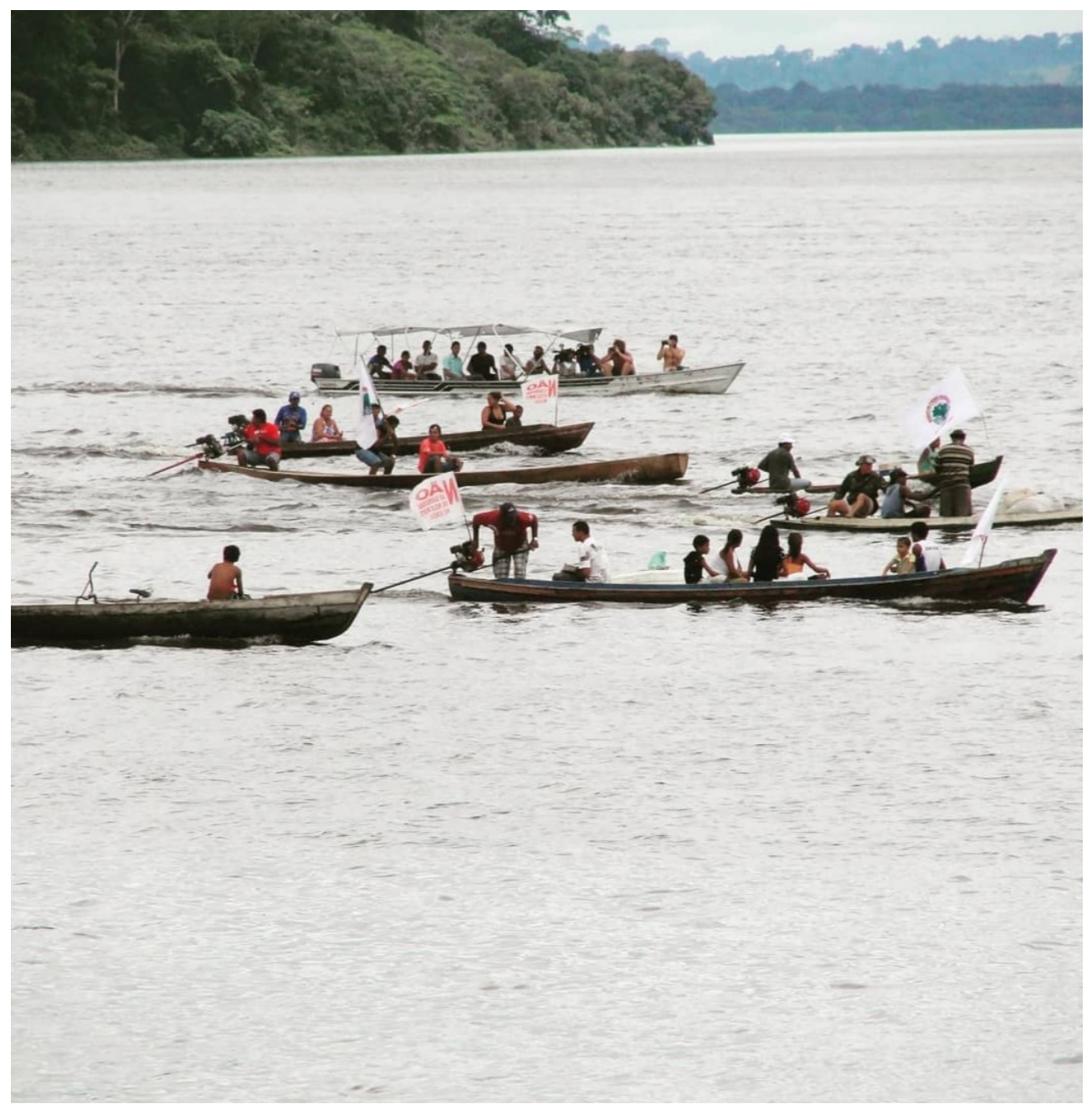

Fig. 1 - Autor desconhecido, Pescadores do Xingu protestando contra Belo Monte, 2011. (Fonte: Acervo do Movimento Xingu Vivo para Sempre.) 

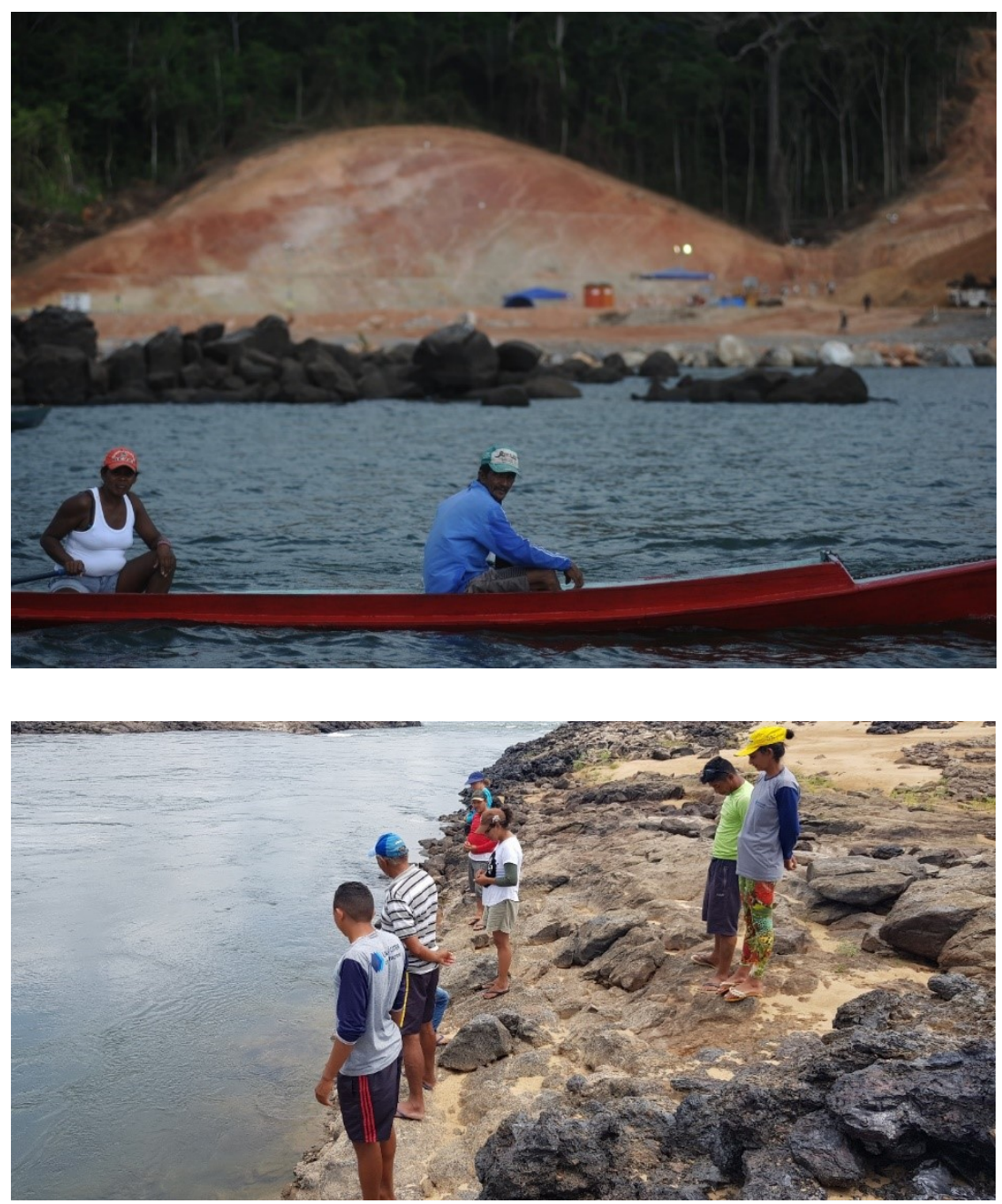

Fig. 2 (no alto) - Lunaé Parracho, Pescadores em defesa de seus territórios, 2012. (Fonte: Acervo do Movimento Xingu Vivo para Sempre.)

Fig. 3 - Mauro Suzuki, Família de pescadores e amigos pedindo pela vida do rio, 2020 (Fonte: Acervo do Movimento Xingu Vivo para Sempre.) 


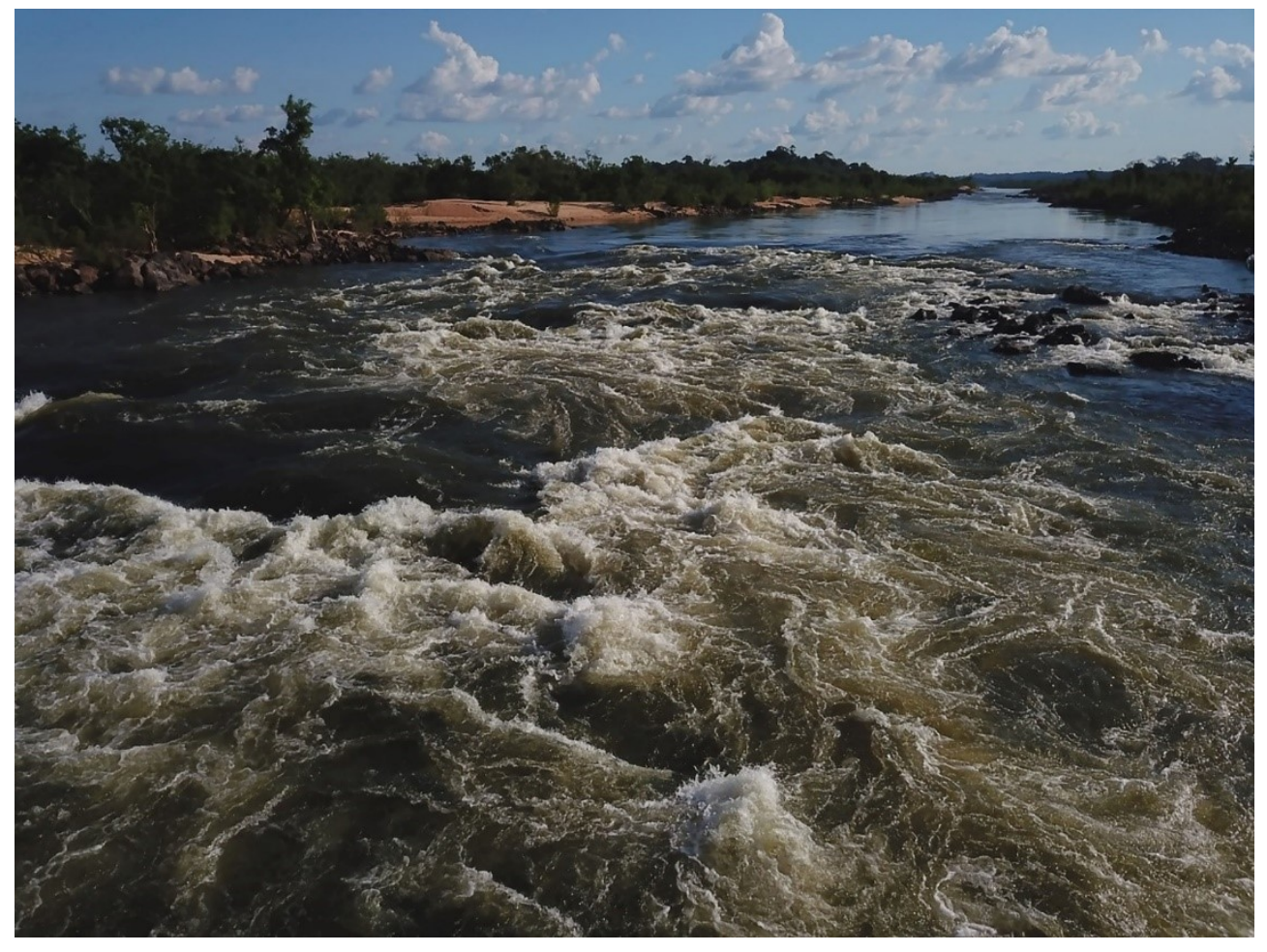

Fig. 4 - Mauro Suzuki, A seca do rio Xingu, 2020.

(Fonte: Acervo do Movimento Xingu Vivo para Sempre.) 


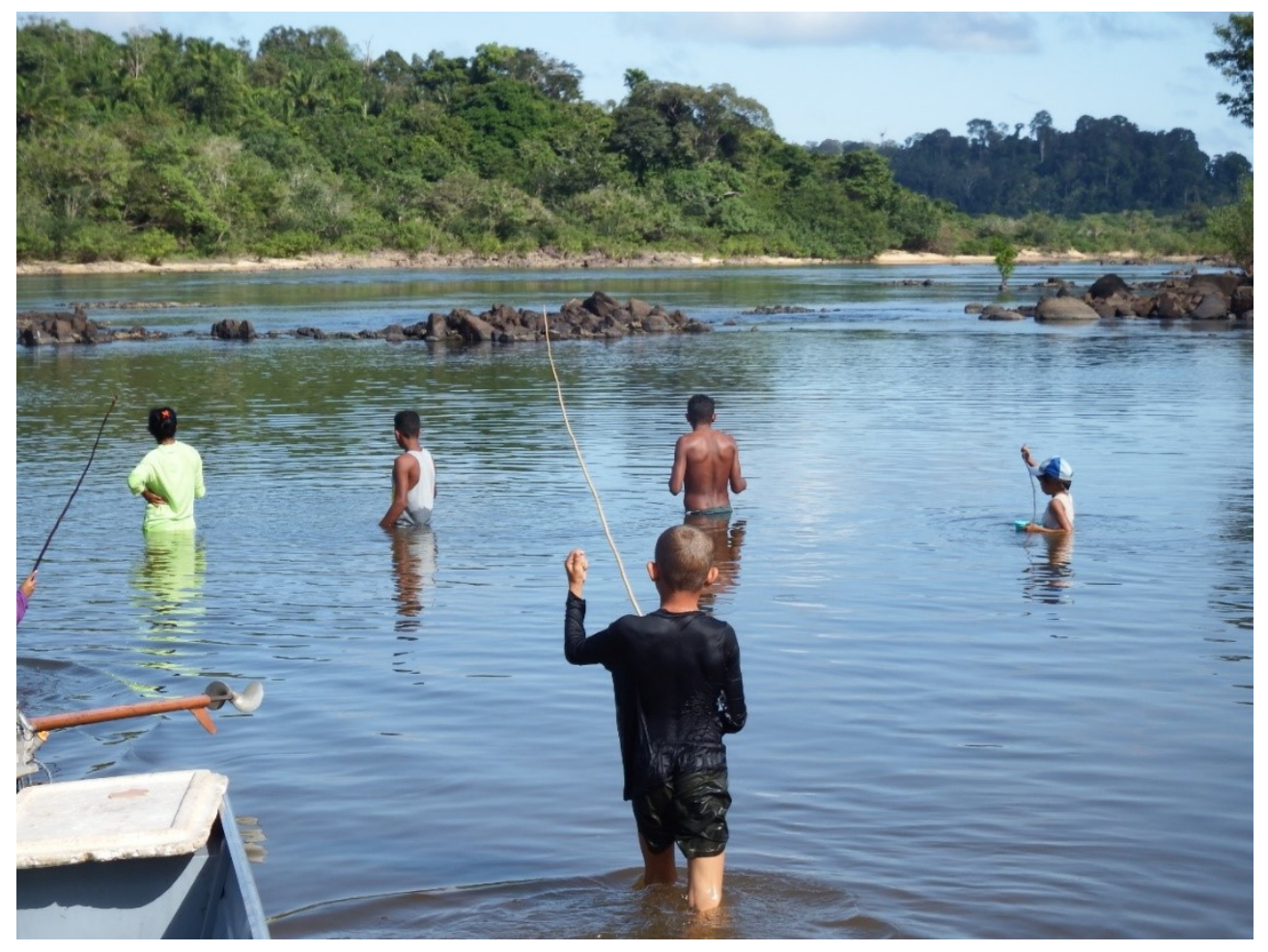

Fig. 5 - Mauro Suzuki, Pescar: conhecimento transmitido há gerações, 2011.

(Fonte: Acervo do Movimento Xingu Vivo para Sempre.) 


\section{Notas}

${ }^{1}$ Áreas alagadas pelos igarapés Ambé, Altamira e Panelas na cidade Altamira, que serviam de moradia.

${ }^{2}$ Espaço de moradia reduzido.

\section{Referências}

AMAMBAI NOTÍCIAS. Grande pescaria em defesa do rio Xingu, contra Belo Monte. Amambai, [2011]. Disponível em https:// www.amambainoticias.com.br/brasil/gran de-pescaria-em-defesa-do-rio-xingu-

\section{MINISTÉRIO DE MINAS E ENERGIA DO} BRASIL; ELETROBRÁS; LEME ENGENHARIA LTDA; CAMAGO CORRÊA; ANDRADE GUTIERREZ; ODEBRECHT. Aproveitamento Hidrelétrico Belo Monte: Relatório de Impacto Ambiental. Cartilha. Brasília, 2009.

COMISSÃO PASTORAL DA TERRA. Grande pescaria em defesa do rio Xingu, contra Belo Monte. [Goiânia], 2011. Disponível em https://www.cptnacional.org.br /publicacoes/noticias/acoes-dos-movimentos/576-grande-pescaria-em-defesado-rio-xingu-contra-belo-monte. Acesso em 20/5/2020.
DUTRA, Manoel. Grande pescaria em defesa do rio Xingu, contra Belo Monte. In DUTRA, Manoel. Jornalismo Ciência Ambiente. Blog. [s. I.]. 11 de março de 2011. Disponível em http://blogmanueldutra. blogspot.com/2011/03/grande-pescariaem-defesa-do-rio-xingu.html. Acesso em $22 / 5 / 2020$.

JORNAL DE BRASÍLIA. Pescadores realizam manifestação contra Belo Monte. [Brasília], 14 de março de 2011. Disponível em https://jornaldebrasilia. com.br/brasil/pescadores-realizammanifestacao-contra-belo-monte/. Acesso em 22/5/2020.

VANNUCHI, Camilo. O direito à comunicação e os desafios da regulação dos meios no Brasil. Galaxia, São Paulo, online, n. 38, 2018, p. 167-180. Disponível em http://www.scielo.br/scielo.php?pid=S198 2-25532018000200167\&script $=$ sci_abstract\&tlng=pt. Acesso em 4/7/2020.

XINGU VIVO. Grande pesca no Xingu protesta contra Belo Monte. [Altamira], 2011. Disponível em https://xinguvivo. org.br/2011/03/13/grande-pesca-no-xingu-protesta-contra-belo-monte-e-seusimpactos/. Acesso em 20/5/2020. 